\title{
IMMUNOSTAINING STATUS OF ANAPLASTIC LYMPHOKINASE IN FEMALE BREAST CANCER.
}

\author{
1. MBBS, M.Phil \\ Assistant Professor Pathology \\ Al-Tibri Medical College, \\ Isra University Karachi Campus. \\ 2. MBBS, M.Phil \\ Senior Lecturer Biochemistry \\ Al-Tibri Medical College, \\ Isra University Karachi Campus. \\ 3. MBBS, M.Phil \\ Assistant Professor Biochemistry \\ Al-Tibri Medical College, \\ Isra University Karachi Campus. \\ 4. BDS, M.Phil \\ Senior Lecturer Pathology \\ Al-Tibri Medical College, \\ Isra University Karachi Campus. \\ 5. MBBS, M.Phil, Ph.D \\ Professor Pathology \\ Al-Tibri Medical College, \\ Isra University Karachi Campus. \\ 6. MBBS \\ Adult Cardiology \\ NICVD Karachi. \\ Correspondence Address: \\ Dr. Syed Naqeeb Ali \\ Assistant Professor Pathology \\ Al-Tibri Medical College, \\ Isra University Karachi Campus. \\ syednaqeeb14@gmail.com \\ Article received on: \\ 01/02/2020 \\ Accepted for publication: \\ $15 / 04 / 2020$
}

\section{INTRODUCTION}

Tumors of breast are most widely recognized malignancy among females globally there after skin disease. Breast tumor counts about $16 \%$ out of complete diseases among females. The frequency is double to colorectal growth and cervical tumors. Throughout globe, the rate of breast tumor varies. Frequencies are lower among low-economic nations but higher among higheconomic nations. Breast tumors are identified in just $5 \%$ of total malignancies of breast in women under age $40 .{ }^{1}$ Females in all ages can be affected by cancer, in elderly, youth population, poor and rich women. It is causing budget related and social issues among Pakistani families. Pakistan is low economic nation and majority populations are residing in rustic territories. In Asia, Pakistan has one of the higher rate with breast cancer. High grade breast cancers with bad prognosis are reported in young females. ${ }^{2}$ Financial issues cause high morbidity rate in Pakistani women. At some phase of life, 1 in 9 Pakistani women is found with breast carcinoma. ${ }^{3}$ The frequency of breast growth was 30-40 in percentage among women in 40-year age range in Pakistan as associated with 10 for each in similar age groups in the West. ${ }^{4}$ One of the most astounding frequency rates in Asia. Pakistani women demonstrate a rate of 50/100,000 and in the neighboring nation India; the frequency rate is $19 / 100,000 .{ }^{5}$ The breast malignancy etiology aren't fully understood, leading to difficulty in suggesting the reason as to why a lady might produce breast tumor while some other might not. Some specific risk factors of breast cancer are ageing, family history, previous breast nodules, 
hormonal factors, uses of birth control pills, alcoholism, obesity and radiations exposure. ${ }^{6}$ Breast tumors are partitioned in subclasses having vital ramifications of prognosis and cure. Pathogenesis represents to chromosomal modifications found within various breast tumor variants as well as to detect particular gene that promote morbidity. mRNA expression levels in estrogen receptors, progesterone receptors as well as HER2 have appeared into future indicator through immunohistochemistry. ${ }^{7}$

A tyrosine kinase receptor known as Anaplastic lymphoma kinase (ALK), dwelling on chromosome 2 p23 was first depicted in a subgroup of anaplastic large cell lymphoma (ALCL) subjects as a major aspect of chromosomal modification with nucleophosmin. ALK has been accounted to be translocated with other combination, for example KIF5B, NPM1, RET, ROS, VCL, TFG, EML4 and MYH9, showing its part in the carcinogenesis of different tumors. Moreover, different results show extra methods of constitutively initiated ALK kinase by mutations and ALK gene enhancement. It has been recommended that the tumor producing part of ALK is most presumably intervened by means of stimulation of tyrosine kinases that advance survival by means of activation through its route for example PI3-kinase/AKT or by hindrance of apoptosis, in this manner prompting multiplication of cells. It has been exhibited that ALK suppression represses development of breast cancer cell lines and furthermore tumor xenografts in models of mouse. ${ }^{8}$

\section{MATERIAL \& METHODS}

The current study was cross-sectional and the duration was from October 2016 to March 2017. All the female patients diagnosed with breast cancer of all ages were included in the study. Metastatic breast carcinoma patients or those were on chemical and radiation treatment was excluded from the study. The ethical approval for the study was taken from Institutional Research and Ethical committee. An informed consent was taken from the patient or her guardian. The biopsy samples were prepared and stained with H\&E. The ALK immunostaining (IHC) was processed on all the biopsy samples which were diagnosed breast cancer on H\&E stain. The immunohistochemistry analysis was carried out by using DAKO Monoclonal Mouse Anti-Human CD246 (ALK) Ab (DAKO, Denmark) with the following instructions;

Tissue sections from paraffin-embedded blocks were collected on clean poly L-lysine coated glass slides, deparaffinized via oven for 1-2 hours at 60 ${ }^{\circ} \mathrm{C}$ and then immersed by three washing steps of xylene till 10 minutes separately, in two washes of $100 \%$ ethanol for 5 minutes respectively and in two washes of $95 \%$ ethanol till 5 minutes each. Then they was immersed twice in distilled water $(\mathrm{dH} 2 \mathrm{O})$ for 5 minutes individually, and was immersed in hydrogen peroxide $1 / 10$ with methanol for 15 minutes. The slides were rinsed two times for 5 minutes as well as washed in Tris buffered saline (TBS) solution, containing $160 \mathrm{gm} \mathrm{NaCl}, 12 \mathrm{gm}$ Tris (hydroxymethyl) and 100cc distilled water with $\mathrm{pH}$ adjusted to 7.6 in concentrated $\mathrm{HCl}$ for 5 minutes. Slides were sited within EDTA solution (0.372 gm EDTA $(\mathrm{C} 10 \mathrm{H} 14 \mathrm{~N} 2 \mathrm{O} 8 \mathrm{Na} 2 \cdot 2 \mathrm{H} 2 \mathrm{O})$ to $1 \mathrm{~L} \mathrm{dH} 2 \mathrm{O}, \mathrm{pH}$ adjusted to 8.0) into the pressure cooker, set for the Biocare Medical Decloaking Chamber follow (SP1 $125^{\circ} \mathrm{C} 30$ seconds and SP2 $90^{\circ} \mathrm{C} 10$ seconds). The slides were then let to cool on the bench for 10 minutes. Slides were rinsed with $\mathrm{dH} 2 \mathrm{O}$. 100-300 $\mu \mathrm{l}$ primary antibody diluted according to the product quide (dilution ratio: 2/100, $\mathrm{pH}: 6)$ and added to each slides, immersed for 40 minutes. Antibody solution removed by placing sections in wash buffer thrice till 5 minutes Upon process development, slides was immersed in $\mathrm{dH} 2 \mathrm{O}$, counterstained in hematoxylin for 15 seconds and washed in $\mathrm{dH} 2 \mathrm{O}$ twice for 5 minutes each. In the Last complete dehydration was done with alcohol, cleared in xylene and mounted. ${ }^{9}$

Staining evaluation was as follows

1. for absent or barely perceptible expression in rare cells

2. for weak to moderate multifocal expression

3. for strong staining in most cells. ${ }^{10}$

\section{RESULTS}

Total 110 female diagnosed patients having cancer of breast were selected in this study. The 
data recorded as laterality of tumor, histological type, tumor grade, involvement of skin, lymph node involvement and lastly menopausal history. Immunohistochemistry for the assessment of ALK was done with microscopic examination.

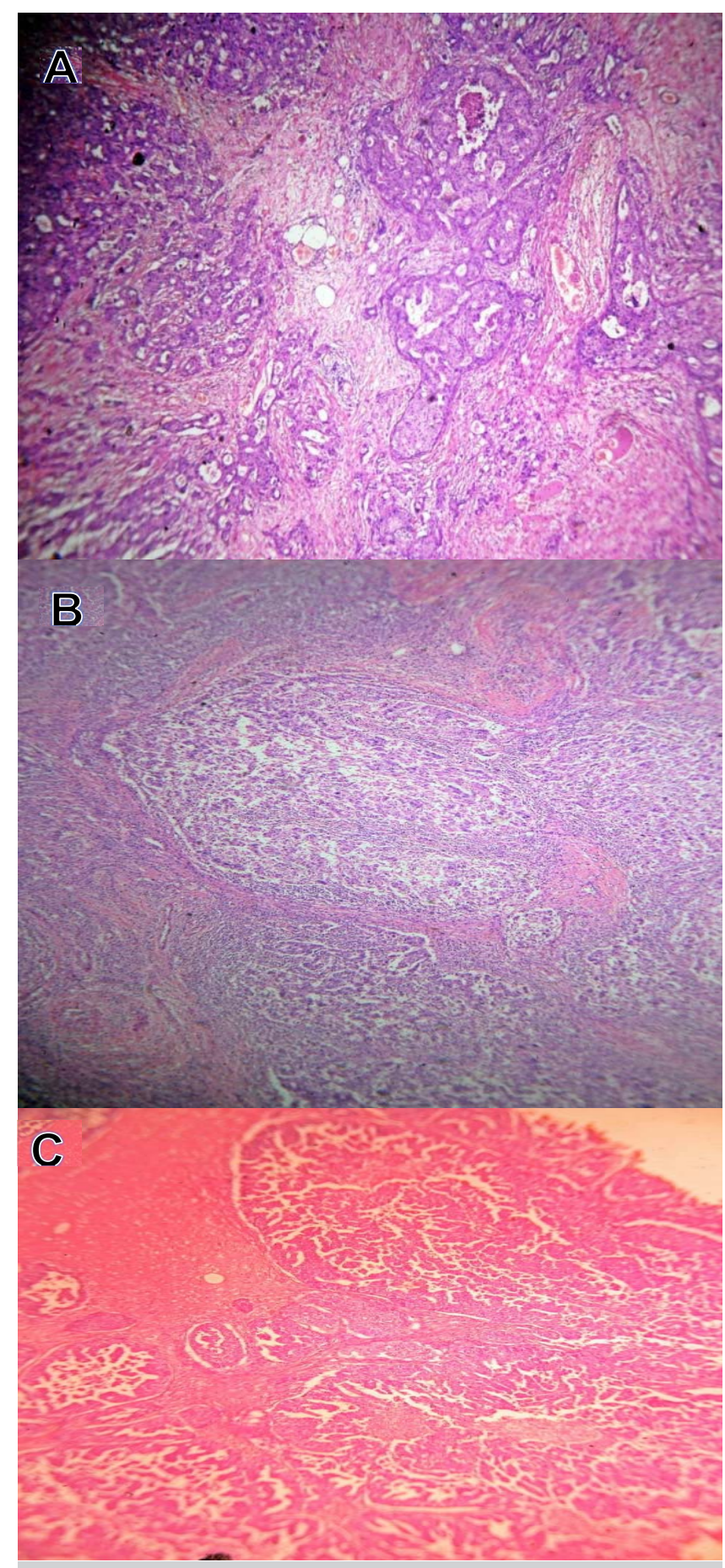

Figure-1. (A) H \& E Staining of invasive ductal carcinoma (B) H \& E Staining of Medullary carcinoma (C) H \& E Staining of Papillary Carcinoma. (100x)
The documented results were then evaluated for association with different variables of breast cancers. An association with a P-value of $\leq 0.05$ was taken to be of significance. Most common positive expression of ALK was observed in 71 (64.5\%) patients and negative in 39 (35.4\%) patients (Table-I). 2(1.8\%) patient had invasive papillary carcinoma, $95(86 \%)$ had invasive ductal carcinoma, 9(8\%) patients had invasive lobular carcinoma and $4(3.6 \%)$ had invasive medullary carcinoma with non-significant P-value of 0.565 was recorded (Table-II).
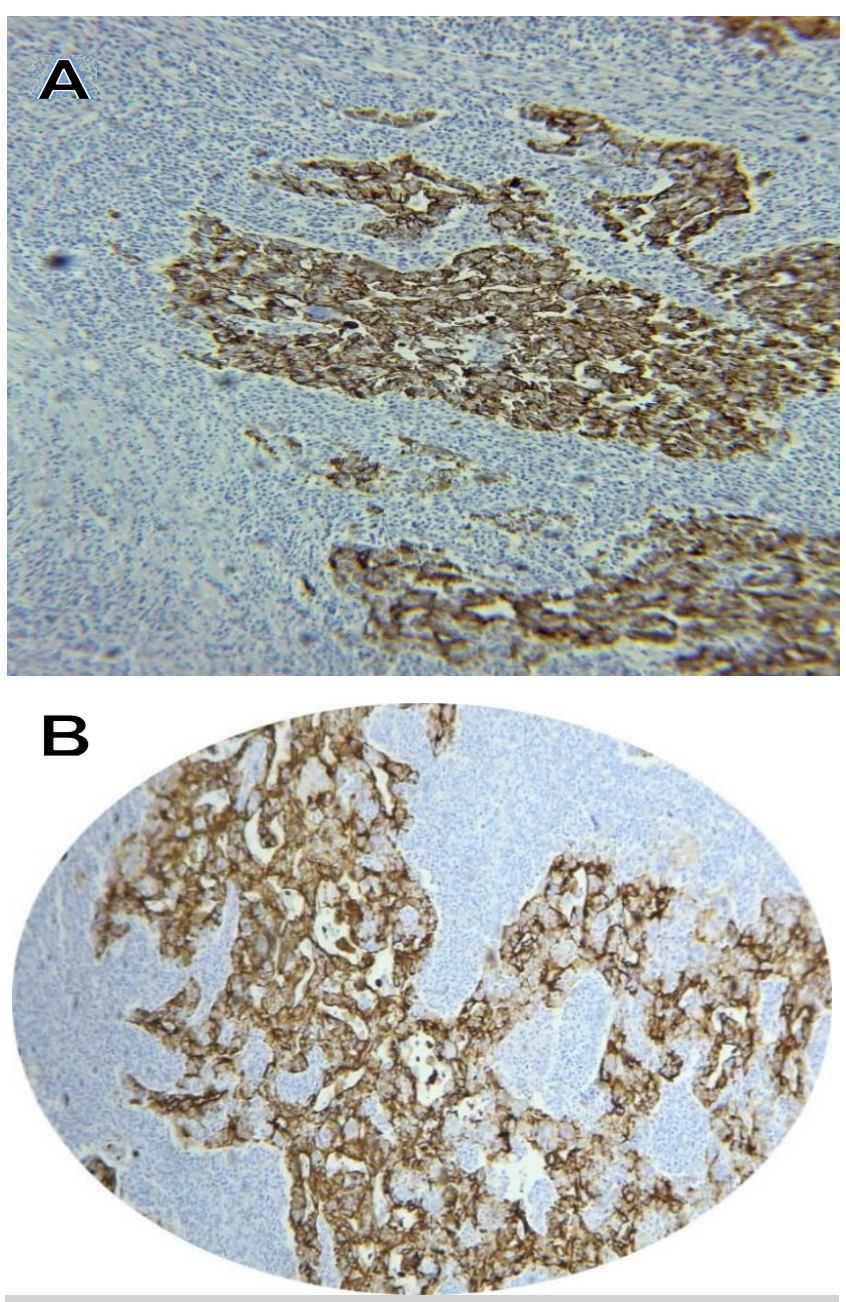

Figure-2. (A) Positive expression of ALK in Ductal Carcinoma (B) Positive expression of ALK in Medullary Carcinoma (100x)

Among 39 ALK negative patients, 23 (56.1\%) had no lymph nodes involvement while 21 (30.4\%) patients were positive lymph nodes. From the 71 ALK positive patients, 18 (43.9\%) were negative for lymph nodes while 48 (69.5\%) patients 
had lymph nodes involvement with significant P-value of 0.042 . Out of 39 patients negative for ALK, 7 (77.7\%) patients had histological grade I, 26 (51.4\%) patients had histological grade II, $10(19.6 \%)$ patients had histological grade III. Amongst the 71 patients positive for ALK, only $2(22.2 \%)$ patient had grade I histology while 24 (48.6\%) had grade II histology and 41 (80.3\%) had grade III histology with significant P-value of 0.003 . A total of 39 ALK negative patients, 33 (77.1\%) patients were negative skin involvement while 8 (20.0\%) patients were positive for involvement of skin. Out of the 71 ALK positive patients, 37 (52.8\%) patients were negative for skin involvement while $32(80.0 \%)$ patients were positive for skin involvement with significant P-value of 0.025 . From the 39 ALK negative patients, 29(46.7\%) patients had tumor in left breast, 17 (36.9.7\%) on the right side while none $(0 \%)$ of the patient had bilateral breast tumor. Among the 71 ALK positive patients, 33(53.2\%) patients had tumor on their left side, $29(63 \%)$ on the right side and 2 (100\%) patients had bilateral breast tumor. Non-significant P-value of 0.107 was reported.

\begin{tabular}{|c|c|c|}
\hline ALK & Frequency & Percen \\
\hline Negative & 39 & 35.4 \\
\hline Positive & 71 & 64.5 \\
\hline Total & 110 & 100.0 \\
\hline
\end{tabular}

Table-I. Status of ALK in breast cancer

\begin{tabular}{|c|c|c|c|c|c|}
\hline \multirow{2}{*}{\multicolumn{2}{|c|}{ Variables }} & \multicolumn{2}{|c|}{ Alk $(n=110)$} & \multirow{3}{*}{$\begin{array}{c}\text { Total } \\
69\end{array}$} & \multirow{2}{*}{ P-Value } \\
\hline & & Negative (39 cases) & Positive (71 cases) & & \\
\hline \multirow{4}{*}{ Menopause } & \multirow{2}{*}{ Pre menopausal } & 33 & 36 & & \multirow{4}{*}{0.092} \\
\hline & & $47.8 \%$ & $52.1 \%$ & $100.0 \%$ & \\
\hline & \multirow{2}{*}{ post menopausal } & 12 & 29 & 41 & \\
\hline & & $29.2 \%$ & $70.7 \%$ & $100.0 \%$ & \\
\hline \multirow{8}{*}{ histological Type } & \multirow{2}{*}{ invasive papillary $\mathrm{Ca}$} & 0 & 2 & 2 & \multirow{8}{*}{0.565} \\
\hline & & $0.0 \%$ & $100.0 \%$ & $100.0 \%$ & \\
\hline & \multirow{2}{*}{ Invasive ductal $\mathrm{Ca}$} & 31 & 64 & 95 & \\
\hline & & $32.6 \%$ & $67.3 \%$ & $100.0 \%$ & \\
\hline & \multirow{2}{*}{ invasive lobular $\mathrm{Ca}$} & 5 & 4 & 9 & \\
\hline & & $55.5 \%$ & $44.4 \%$ & $100.0 \%$ & \\
\hline & \multirow{2}{*}{ invasive medullary $\mathrm{Ca}$} & 1 & 3 & 4 & \\
\hline & & $25.0 \%$ & $75.0 \%$ & $100.0 \%$ & \\
\hline \multirow{7}{*}{ Tumor laterality } & \multirow{2}{*}{ Left } & 29 & 33 & 62 & \multirow{7}{*}{0.107} \\
\hline & & 46.7 & $53.2 \%$ & $100.0 \%$ & \\
\hline & \multirow{2}{*}{ Right } & 17 & 29 & 46 & \\
\hline & & $36.9 \%$ & $63.0 \%$ & $100.0 \%$ & \\
\hline & \multirow{3}{*}{ Bilateral } & 0 & 2 & 2 & \\
\hline & & $0.0 \%$ & $100.0 \%$ & $100.0 \%$ & \\
\hline & & $36.0 \%$ & $64.0 \%$ & $100.0 \%$ & \\
\hline \multirow[t]{4}{*}{ lymph Node } & \multirow{2}{*}{ Negative } & 23 & 18 & 41 & \multirow{4}{*}{0.042} \\
\hline & & $56.1 \%$ & $43.9 \%$ & $100.0 \%$ & \\
\hline & \multirow{2}{*}{ Positive } & 21 & 48 & 69 & \\
\hline & & $30.4 \%$ & $69.5 \%$ & $100.0 \%$ & \\
\hline \multirow[t]{4}{*}{ skin Involvement } & \multirow{2}{*}{ Negative } & 33 & 37 & 70 & \multirow{4}{*}{0.025} \\
\hline & & $47.1 \%$ & $52.8 \%$ & $100.0 \%$ & \\
\hline & \multirow{2}{*}{ Positive } & 8 & 32 & 40 & \\
\hline & & $20.0 \%$ & $80.0 \%$ & $100.0 \%$ & \\
\hline \multirow[t]{6}{*}{ Histological grade } & I & 7 & 2 & 9 & \multirow{6}{*}{0.003} \\
\hline & & $77.7 \%$ & $22.2 \%$ & $100.0 \%$ & \\
\hline & II & 26 & 24 & 50 & \\
\hline & & $51.4 \%$ & $48.6 \%$ & $100.0 \%$ & \\
\hline & III & 10 & 41 & 51 & \\
\hline & & $19.6 \%$ & $80.3 \%$ & $100.0 \%$ & \\
\hline
\end{tabular}




\section{DISCUSSION}

Breast malignancy is one of the most commonest carcinoma around the globe instead of progress in cancer management, breast cancer enhances a main causative factor in spread of different breast lesions and death in patients having breast malignancies. ${ }^{11}$ Different studies reveal that ALK tyrosine kinase receptor is a reliable immunomarker and a good therapeutic predictor in managing a large number of breast malignancies. ${ }^{12,13}$ Hence, in order to learn more on the prevalence and clinical significance of ALK overexpression and its association with clinical parameters in Middle Eastern breast cancer, we comprehensively investigated protein expression of ALK In the current study, pre-menopausal status was seen in $69(62.7 \%)$ whereas postmenopausal cases were 41 (37.2\%). Shankar A et $\mathrm{al}^{14}$ reported $25.7 \%$ were pre-menopausal and $74.3 \%$ post-menopausal females in his study. Whereas Verbeek FPR et $\mathrm{al}^{15}$ reported pre-menopause status in $26 \%$ patients and postmenopause status in $74 \%$ of the patients.

Current research reveals the histological type as invasive ductal carcinoma was observed in 95(86.3\%) patients, invasive lobular carcinoma and invasive medullary carcinoma was seen in $9(8.1 \%)$ and $4(3.6 \%)$ patients, whereas invasive papillary carcinoma were found in only $2(1.8 \%)$ cases. However Shankar A et $\mathrm{al}^{14}$ showed a similar figure in different histological types invasive ductal carcinoma was observed in $90.9 \%$, invasive lobular carcinoma $6.76 \%$ and invasive medullary carcinoma in $1.87 \%$ and invasive papillary carcinoma was seen in $0.18 \%$ patients.

Similar results were also reported by Mehrjardi AZ et al. ${ }^{9}$ Invasive ductal carcinoma was observed in $88 \%$, Invasive lobular carcinoma found in $8 \%$ and Invasive medullary carcinoma in $4 \%$ of the breast cancer patients in his study. Regarding tumor laterality, in most cases of breast cancer $62(56.3 \%)$ patients left breast involvement was seen, however $46(41.8 \%)$ had right breast involvement while only $2(1.8 \%)$ were found with bilateral breast involvement. Similar results are showed by Mahmoud MM et $\mathrm{al}^{16}$ that left breast was found involved in 75 (54.3\%) patients, right breast was involved in 58 (42\%) and bilateral tumor was observed in $5(3.7 \%)$ patients. In this study positive lymph node was ssen in 69 (62.7\%) cases and 41 (37.7\%) were seen negative. Similar results are reported by Devi PU et al ${ }^{17}$ that positive lymph node was found in $53.6 \%$ patients and negative lymph node was observed in $46.3 \%$.

In current study, skin involvement with tumor tissue was noticed in 40 (36.3.\%) and skin free of tumor tissue was seen in 70 (63..6\%) patients. In terms of skin involvement Mahmood $\mathrm{H}$ et $\mathrm{al}^{18}$ reported similar results $46.4 \%$ positive skin involvement whereas no skin involvement was seen in $53.6 \%$ of the cases. In the present study histological grade-I was found in 9 (8.1\%) patients, grade-II in 50 (45..4\%) and grade-III was seen in 51 (46.3\%) cases. Mehrjardi AZ et al ${ }^{9}$ also showed same results with the recent study that grade-I was observed in $7.6 \%$ patients, grade-II in $31.5 \%$ and grade-III was noticed in $60.9 \%$ of the patients. In Li Ding ${ }^{19}$ study similar observations were noticed with histological grade-l in 7.6\% cases, $53 \%$ in grade-II and $38 \%$ in grade-III.

In this study, positive cases of ALK was observed in $71(64.5 \%)$ patients and negative in 39 (35.4.1\%) patients whereas, Mehrjardi AZ et $\mathrm{al}^{9}$ reported $47 \%$ positive cases and $53 \%$ negative cases. In this study, significant association ( $P$ $<0.05)$ was found between histological grade, Lymph node involvement and skin involvement when compared with ALK., whereas menopausal status, histological type, tumor laterality were found to be insignificant when compared with ALK positivity. Current study reveals significant association of histological grade with ALK (P-value 0.003). Similar result was found in Siraj AK et al ${ }^{20}$ study with significance (P-value 0003).

\section{CONCLUSION}

In conclusion, immunostaining expression of ALK was investigated and the relationship of immunomarker ALK with different clinicopathological variables was studied. Present study indicated significant ALK relationship with histological grade, lymph node involvement and skin involvement.

Copyright(C) 15 Apr, 2020. 


\section{REFERENCES}

1. Shahida F. Institute of nuclear medicine and oncology Lahore. Breast cancer incidence alarming in Pakistan. The Dawn. 2015 Feb 5: 5.

2. Menhas R, Umer S. Breast Cancer among Pakistani Women. Iranian journal of public health. 2015 Apr; 44(4):586-7.

3. Sohail S, Alam SN. Breast cancer in Pakistan: Awareness and early detection. J Coll Phys Surg Pak. 2007 17: 711 - 712.

4. Lubna V, Pakistan has highest incidence of breast cancer in Asia. The Dawn. 2017 Nov 27; 7.

5. Rasheed R. Breast cancer. Journal of the College of Physicians and Surgeons Pakistan 2013; 23(10):766768.

6. Mansfield CM. The etiology of breast cancer. Journal of the National Medical Association.2013; 85(3):217221.

7. Hu X, Stern HM, Ge L, O'Brien C, Haydu L, Honchell CD et al. Genetic alterations and oncogenic pathways associated with breast cancer subtypes. Molecular Cancer Research. 2009 Apr 1; 7(4):511-22.

8. Kim MH, Lee S, Koo JS, Jung KH, Park IH, Jeong J et al. Anaplastic lymphoma kinase gene copy number gain in inflammatory breast cancer (IBC): prevalence, clinicopathologic features and prognostic implication. PloS one. 2015 24; 10(3): 1-13.

9. Mehrjardi AZ, Vaghefi A. Expression of anaplastic lymphoma kinase protein in human breast cancer. Iran J Pathol. 2013; 8(1):27-35.

10. Wang J, Shen Q, Shi Q, Yu B, Wang X, Cheng K, et al. Detection of ALK protein expression in lung squamous cell carcinomas by immunohistochemistry. J Exp Clin Cancer Res. 2014; 33(1):1-7.

11. Ekwueme DU, Guy Jr GP, Rim SH, White A, Hall IJ, Fairley $\mathrm{TL}$, et al. Health and economic impact of breast cancer mortality in young women. Am J Prev Med. 2014; 46(7):1-9.
12. Kelleher FC, McDermott $R$. The emerging pathogenic and therapeutic importance of the anaplastic lymphoma kinase gene. Eur J Cancer. 2010; 46 (13):2357-2368.

13. Grande E, Bolos MV, Arriola E. Targeting oncogenic ALK: A promising strategy for cancer treatment. Mol Cancer Ther. 2011; 10(4):569-579.

14. Shankar A, Roy S, Malik A, Kamal VK, Bhandari R, Kishor $\mathrm{K}$ et al. Contralateral breast cancer: A clinicopathological study of second primaries in opposite breasts after treatment of breast malignancy. Asian Pacific Journal of Cancer Prevention. 2015; 16(3):12071211.

15. Verbeek FPR, Troyan SL, Mieog JSD, Liefers GJ, Moffitt $L A$, Rosenberg $M$ et al. Near-infrared fluorescence sentinel lymph node mapping in breast cancer: A multicenter experience. Breast Cancer Res Treat. 2014; 143(2):333-342.

16. Mahmoud MM. Breast Cancer in Kirkuk City, Hormone Receptors Status (Estrogen and Progesterone) and Her-2/Neu and Their Correlation with Other Pathologic Prognostic Variables. Diyala Journal of Medicine. 2014; 6(1): 1-14.

17. Devi PU, Prasad U, Lakshmi AB, Rao GS. A study of correlation of expression of ER, PR and HER2/neu receptor status with clinico-pathological parameters in breast carcinoma at a Tertiary Care Centre. International Journal of Research in Medical Sciences. 2015; 3(1):165-173.

18. Mahmood H, Faheem M, Mahmood S, Sadiq M, Irfan J. Impact of age, tumor size, lymph node metastasis, stage, receptor status and menopausal status on overall survival of breast cancer patients in Pakistan. Asian Pacific Journal of Cancer Prevention. 2015; 16 (3):1019-1024.

19. Ding $L$, Zhang $Z, X u Y$, Zhang $Y$. Comparative study of Her-2, p53, Ki-67 expression and clinicopathological characteristics of breast cancer in a cohort of northern China female patients. Bioengineered. 2017; $1(0): 1-10$

20. Siraj AK, Beg S, Jehan Z, Prabhakaran S, Ahmed M, Hussain AR, et al. ALK alteration is a frequent event in aggressive breast cancers. Breast Cancer Res. 2015; 17(1):1-2. 


\begin{tabular}{|c|c|c|c|}
\hline \multicolumn{4}{|c|}{ AUTHORSHIP AND CONTRIBUTION DECLARATION } \\
\hline Sr. \# & Author(s) Full Name & Contribution to the paper & Author(s) Signature \\
\hline 1 & Syed Naqeeb Ali & $\begin{array}{l}\text { Writing of the article and Final } \\
\text { approval of article. }\end{array}$ & \\
\hline 2 & Syed Liaquat Ali & $\begin{array}{l}\text { Analysis and interpretation of } \\
\text { data. }\end{array}$ & \\
\hline 3 & Ghazala Panhwar & Drafting of the article. & \\
\hline 4 & Sarwat Batool & Statistical expertise. & \\
\hline 5 & Anila Qureshi & $\begin{array}{l}\text { Critical revision of the article for } \\
\text { major corrections. }\end{array}$ & \\
\hline 6 & Momina Naseer & Data collection. & \\
\hline
\end{tabular}

